\title{
Buenos Aires: la fragmentación en los intersticios de una sociedad polarizada*
}

\author{
MARIE-FRANCE PRÉVÔT-SCHAPIRA** Y RODRIGO CATTANEO PINEDA*** \\ ** Profesora de Geografía, Universidad París 8. Investigadora Centre de recherche et de Documentation sur l'Amé- \\ rique latine (CREDAL). \\ *** Profesor Auxiliar de Geografía y Doctorante, Universidad París 8 y Centre de recherche et de Documentation \\ sur l'Amérique latine (CREDAL).
}

\begin{abstract}
In Latin America, the term "fragmentation" has been the subject of several significant academic debates. Used in all fields of urban research on Latin-American cities (political, economic, and spatial analysis), its diffusion resulted in its adoption as the foundational principle of a new urban model, the fragmented city. Based on empirical research on Ciudad Evita, we argue that fragmentation is a phenomenon that can also be observed in the interstices of an unequal society in the form of actors' micro-strategies of social distinction and negotiation in the context of social polarization and contradictory and intermittent urban policies.
\end{abstract}

KEYWORDS: fragmentation, segregation, suburbs, metropolis, Buenos Aires.

RESUMEN En América Latina la utilización del término fragmentación ha sido objeto de importantes debates académicos. Utilizado en todos los campos de la investigación -político, económico y espacial- de las grandes metrópolis latinoamericanas, su propagación desembocó en su adopción como principio fundador de un nuevo modelo de ciudad: la ciudad fragmentada. A partir del ejemplo de Ciudad Evita, sostenemos que la fragmentación es un fenómeno reconocible también en los intersticios de una sociedad polarizada, bajo la forma de micro-estrategias de distinción y de negociación sobre un fondo de polarización social y de política urbana intermitente y contradictoria.

PALABRAS CLAVES: fragmentación, segregación, suburbios, metrópolis, Buenos Aires.

\footnotetext{
* Esta investigación fue realizada gracias al apoyo de la misión PUCA Habiter quelle ville de l'Agence Nationale de la Recherche y del programa ANR-SUDS-Metraljeux.

Recibido el 19 de octubre de 2008, aprobado el 4 de noviembre de 2008.

Correspondencia: Marie-France Prévôt-Schapira, CNRS-CREDAL, 27 rue Paul Bert, 94204 Ivry-sur-Seine, France. E-mail: schapira@ivry.cnrs.fr. Rodrigo Cattaneo, 9, rue Bridaine 75017 Paris, France. E-mail: rodrigo. cattaneo@univ-paris8.fr.
} 


\section{Introducción}

El empleo del término fragmentación ha sido objeto de numerosas investigaciones y controversias durante los últimos años. No es nuestra intención resumir la abundante literatura, tanto geográfica como sociológica, que se ha dado a partir del estudio de sus usos (Laumonier, 2004). Pero es conveniente señalar que para el caso de América Latina, el autor Vidal (1995) jugó un rol precursor, trazando la génesis de este término y su filiación con los análisis realizados en la América anglo-sajona sobre la ciudad global y los nuevos modos de gobierno de las ciudades y de sus poblaciones. En el continente latinoamericano esta noción fue introducida por primera vez en Brasil, para describir las evoluciones de la economía metropolitana en el nuevo marco de la globalización. Santos (1990) recalcaba, así, que el modelo tradicional "centro-periferia" de descripción de la ciudad latinoamericana se había invalidado progresivamente por los efectos de la crisis del fordismo periférico y por la aparición de nuevas formas de segregación urbana en la ciudad consolidada. Pero es tan solo a partir de los años noventa que este término alcanza una franca difusión, asociado en general a la idea de crisis urbana, en una coyuntura marcada por transformaciones espectaculares de las dinámicas espaciales y de las modalidades de gestión metropolitana; cambios ligados a su vez a nuevas formas de regulación política y económica en un contexto de atenuación del crecimiento demográfico.

¿Este término sustituye por ende a la noción de segregación? Con respecto a esta última, en su doble acepción de confinamiento y de desigualdad, ¿cuál es el aporte conceptual de este vocablo más reciente? En un artículo publicado en la revista Perfiles Latinoamericanos, Prévôt-Schapira (2001) realizó un rápido balance crítico e histórico del vocabulario utilizado para la descripción de la ciudad, desde la temática de la marginalidad hasta la innovación de la fragmentación. Esto, con el objetivo de destacar la utilización bastante tardía del término "segregación" en los estudios latinoamericanos, debido a su asociación a la problemática norteamericana del análisis de la traducción espacial de la cuestión racial, prefiriendo por tanto la utilización de expresiones como "división social del espacio", a pesar de que la segregación étnica fuese parte de los orígenes mismos de la ciudad latinoamericana. En esta línea, nos preguntamos ¿en qué medida el término fragmentación es una nueva tentativa de interpretación de la segmentación social y espacial de los espacios urbanos? ¿Cómo nos permite examinar en toda su complejidad las lógicas que sustentan estos fenómenos?

\section{¿Se puede hablar de ruptura con los procesos observados en el pasado?}

La transición de un término a otro plantea la siguiente pregunta: ¿los cambios ligados al fenómeno de la metropolización observables en el espacio urbano (urban sprawl, gentrification, barrios cerrados) implican un recrudecimiento, o incluso una exacerbación de la segregación existente en las ciudades de América Latina, o designan más bien la aparición de nuevas dinámicas y dibujos de las fronteras intra-urbanas? Esta última hipótesis se articula con otra: ¿estamos en presencia de un nuevo modelo de ciudad, la ciudad fragmentada, en ruptura con el modelo de la fase de rápida urbanización de las grandes metrópolis latinoamericanas, durante los años de crecimiento industrial y de integración populista (Prévôt-Schapira, 1999)? 
En el caso bonaerense, sostenemos la idea que el cambio en la orientación económica, la crisis de los años ochenta y las reformas neoliberales de los años noventa, que conllevaron el empobrecimiento y el desempleo de segmentos enteros de la sociedad, modificaron profundamente los mecanismos de integración en la ciudad y en el territorio, marcando así el cierre del ciclo abierto por la federalización de la capital (1880). El término fragmentación recobra todo su sentido en contraste con la historia de una ciudad que fue concebida como una "máquina de reformar”, destinada a modernizar el país y a integrar a sus habitantes (Gorelik, 1997). La urbanización de la ciudad y de su inmensa periferia no puede ser disociada de la fuerte movilidad social ascendente de los años 40-70 y del acceso masivo a la propiedad de la vivienda ("la casa propia”) y a un empleo. Pero los mecanismos sobre los cuales reposaban estas modalidades de integración social fueron gravemente deteriorados por las crisis y la política de reajuste de los ańos noventa. Por ende, una lectura espacial de la agudización de las desigualdades necesita sobrepasar la oposición más notoria entre los dos extremos de la escala social, para favorecer el análisis de la difusión de la pobreza en los loteos suburbanos así como en los barrios de la pequeña clase media de la capital. Es en estos espacios intermedios, entre las grandes concentraciones de pobreza y los barrios privados, que se encuentra en marcha el proceso de atomización privatizante. La fragmentación aparece, así, como un fenómeno íntimamente relacionado con la atormentada historia política y económica de país, y con las respuestas, tanto individuales como colectivas, de negociación, de adaptación y de instrumentalización de sus diferentes avatares. Ciertos comportamientos y estrategias, en un marco legislativo plástico y variable en el tiempo, se revelan entonces como productores de fragmentación urbana.

¿En qué medida podemos extender estas observaciones al conjunto de las ciudades latinoamericanas? Pregunta en efecto pertinente, ya que si se observa una progresión fuerte del trabajo informal y precario en casi todo el continente, el desplome brutal de una sociedad salarial sólidamente constituida en Buenos Aires es una transformación mayor que no se puede encontrar en ninguna otra parte con tal amplitud. Ya es prácticamente una regla el afirmar que las evoluciones socio-espaciales de las metrópolis de América Latina han sido fuertemente determinadas por sus herencias urbanas y sociales específicas, y por las distintas modalidades de gobernar la ciudad. No obstante, creemos posible el intentar identificar ciertas grandes tendencias y regularidades.

\section{Las tres dinámicas de la fragmentación urbana}

En América Latina, la utilización del término fragmentación se despliega en tres grandes direcciones: el estudio de las políticas públicas y de los nuevos modos de gobernanza de las metrópolis continentales, la caracterización de las transformaciones económicas asociadas a la globalización y a las nuevas estrategias del management empresarial, y, por último, el análisis de la relación, muchas veces contradictoria, entre cambio social y evoluciones de la estructura urbana. La interrelación entre estas tres lógicas multiplica los puntos de fricción e intensifica los antagonismos entre los actores y las redes que se disputan y se reparten el espacio urbano, en circunstancias marcadas a la vez por el dinamismo económico y el crecimiento de las desigualdades y de la pobreza. 


\section{Competición institucional y segmentación de la acción pública.}

La fragmentación política e institucional coincide -tanto en América Latina como en Europa-con procesos de descentralización que debilitan o modifican el rol de los Estados. De manera más o menos importante según los países, los gobiernos locales han conocido una ampliación de su campo de intervención, impulsados por las consignas de los organismos internacionales (Agenda XXI, Buen Gobierno, Best Practices, etc.) y las exigencias de diversas organizaciones populares e instancias de participación popular que, en muchos casos, han contribuido ellas mismas a desarrollar. Pero está demás decir que la transferencia de prerrogativas y de poderes a niveles inferiores de gobierno ha complejizado los dispositivos políticos e institucionales de estas vastas metrópolis, divididas, e inclusive fracturadas, en diferentes entidades político-administrativas. Si el crecimiento de la población a contar de los años 80 se ha reducido, la expansión del área metropolitana prosigue. En muchos casos, ante la ausencia de mecanismos de cooperación, la descentralización desembocó en una cristalización de las fronteras políticas, y en ciertos casos hasta en su santuarización.

Esta fragmentación es más o menos intensa según la configuración metropolitana. En muchos planos, la aglomeración de Buenos Aires es uno de los ejemplos más notorios de metrópolis dividida. A la ciudad centro, autónoma desde 1996 y poblada por una clase media "progresista" , se oponen las municipalidades periféricas, por supuesto diversas, pero empobrecidas en su gran mayoría, y en las cuales se enraízan los bastiones del peronismo y de los movimientos piqueteros. En su libro Cities without suburbs, Rusk (1993) constata que las ciudades más eficientes son aquellas que anexaron su territorio urbano en la medida que fueron extendiéndose, ya que el white flight hacia los espacios circundantes tendía a empobrecer los cascos antiguos. Pero esto nunca fue el caso en América Latina. Si durante las décadas de los cincuenta y sesenta, los centros históricos también conocieron un proceso progresivo de éxodo de sus élites, el principal sustento del urban sprawl latino fueron las migraciones internas de las clases populares. De hecho, el debate sobre la dimensión metropolitana del gobierno fue planteado precozmente en Buenos Aires, en la década de los años treinta, cuando la urbanización sobrepasó la cintura periférica de la Avenida del General Paz, frontera que separaba la ciudad de su periferia. Pero la materialización de esta ruptura a fines de los años treinta sedimentó la ruptura -a la vez política, social y cultural-, entre dos espacios desde entonces disímiles. Estos nuevos municipios periféricos se convirtieron así en espacios de acumulación de un poder político -tanto en términos de prebendas materiales como de acceso a responsabilidades públicas- en competencia para su mantenimiento con la ciudad-centro y entre ellos mismos. En Buenos Aires como en el resto del continente, las reformas institucionales se estrellan contra estas fronteras políticas y raros son los casos de ciudades que han logrado establecer estructuras de cooperación de escala metropolitana. La propagación del principio de subsidiaridad y la adopción generalizada de una política de descentralización de las prerrogativas públicas fortaleció las lógicas centrifugas de los espacios periféricos. Libertun de Duren (2006) examina en un artículo reciente los efectos de la descentralización de la gestión de las normas urbanísticas en la emergencia de nuevos esquemas de localización de los productos inmobiliarios "cerrados" en la periferia bonaerense. Gracias a esta mayor capacidad de negociación, los municipios más acomodados pudieron llevar a cabo una gestión de la utilización del suelo más acorde con sus intereses. En cambio, las comunas pobres o 
de la segunda corona, como es el caso de Pilar, utilizaron la modificación del código de urbanismo local como un dispositivo de atracción de la inversión inmobiliaria. En respuesta a las múltiples, y a veces opuestas, estrategias desarrolladas (aplicación legalista de los reglamentos existentes, lógica del acomodamiento "caso por caso" o asociación explícita con los promotores inmobiliarios), el capital inmobiliario favoreció los espacios que habían adoptado la lectura más flexible de la normativa y de la zonificación urbana. Los barrios cerrados se concentran así en las comunas más pobres y con menor capacidad o voluntad de fiscalización, favoreciendo así la polarización social de estos territorios y acrecentando los fenómenos de competencia entre distintos espacios periféricos.

Pero la segmentación urbana también puede ser favorecida por la adopción de nuevas modalidades de intervención pública en la esfera urbana, y en particular por la tendencia a la territorialización de la cuestión social. Analizando las políticas de mitigación de los efectos negativos de los planes de ajuste en los suburbios bonaerenses, Prévôt-Schapira (2000) insiste sobre la importancia del "territorio" en sus nuevos lineamientos programáticos. Esta noción fue presentada como una llave de lectura pertinente de la heterogeneidad social de estos espacios y como un medio de focalización de recursos escasos en las poblaciones más vulnerables; aunque la distribución de la ayuda social a través de circuitos políticos fuertemente enraizados en la escala local tuvo también consecuencias políticas, en el sentido de un reforzamiento de los clientelismos espaciales. El Plan de Justicia Social para la reparación histórica del Conurbano tenía, así, un doble objetivo: la intervención en las "zonas desfavorecidas", percibidas como potencialmente explosivas, y el control a través de las alcaldías de una de las zonas más importantes en el tablero político nacional. Esta espacialización de la cuestión social ha marginado la discusión sobre los procesos de empobrecimiento y su propagación difusa en la sociedad argentina, beneficiando más bien una reflexión puramente técnica sobre los perímetros y las categorías de la pobreza. El reforzamiento de las lógicas clientelistas y la multiplicación de los perímetros de intervención desembocan en la creación de nuevas fronteras y fenómenos de competencia en los suburbios.

\section{La economia urbana entre lugares, redes y flujos}

La imagen de la fragmentación fue utilizada tempranamente en investigaciones sobre economía metropolitana, para traducir el movimiento de dislocación del tejido productivo de las grandes ciudades en función de su mayor o menor conexión con una economía-mundo en mutación. La globalización reforzó las lógicas de competencia y de emulación entre los distintos territorios de la metrópolis, en un contexto de diversificación creciente de los actores económicos y de sus organizaciones, y de ruptura con respecto a su pasado "corporativista". De esta manera, el movimiento de privatización de los espacios y de los servicios ha reducido fuertemente los márgenes de maniobra de las colectividades locales y de los Estados. Los efectos de la globalización económica sobre la configuración urbana pueden ser estudiados según tres configuraciones. La conjunción del crecimiento económico con el desempleo de masa y la precariedad suscitaron una tendencia a la polarización de la sociedad y a la dualización del espacio. Castells (Pflieger, 2006) distingue así en la ciudad dual el espacio de los flujos y el espacio de los lugares. Esta concepción de la ciudad traduce la progresiva desarticulación entre lo global y lo local a escala metropolitana. El espacio de los flujos concentra así las actividades relacionadas con la creación y la apropiación de los valores generados por las redes de la economía globalizada, mientras tanto vastas extensiones del territorio metropolitano funcionan todavía según la dinámica del lugar 
y de la contigüidad. Ciccolella (1999) advierte que en el caso de Buenos Aires, los procesos de privatización, desregulación y apertura económica aceleraron la diferenciación metropolitana interna entre los espacios del capitalismo postfordista y una mancha urbana cada vez más marginada. La modernización relativa del aparato productivo fue pagada por un distanciamiento social creciente y por la desarticulación de la horizontalidad urbana.

La imagen de la ciudad globalizada como un sistema de redes y de flujos fue ampliada por Graham y Marvin (1996) en su análisis de las infraestructuras de servicios y de la condición urbana. Si en la ciudad moderna las redes de servicio fueron un factor de integración social y de consolidación de la unidad de los diferentes espacios urbanos, la gestión espacial y socialmente diferenciada de los servicios por medio de premium networks, destinadas a satisfacer la demanda solvente, favorece hoy en día el proceso de segmentación y de diferenciación urbana (splintering urbanism). Pero si los riesgos de desolidarización son reales, estos no son necesariamente unívocos, sino que dependen de los arbitrajes efectuados y de la regulación política de la diversificación de los dispositivos de servicio (Jaglin, 2007).

En América Latina, donde el Estado había sido particularmente influyente en la constitución de una base productiva nacional, estas evoluciones son especialmente notorias. Las grandes empresas nacionales e internacionales se han convertido en actores que definen sus propios perímetros de intervención. En Buenos Aires, la ola de privatizaciones de los noventa permitió el establecimiento de una nueva generación de actores cada vez más disociados del campo político-administrativo, y la afirmación de una estrategia administrativa que favorecía una gestión diferenciada del espacio. Por una parte, podemos observar el peso creciente de los stakeholders, término del ámbito financiero adoptado por los organismos internacionales para designar a aquellos actores que son protagonistas de la organización de la ciudad, es decir, tanto los grandes operadores de los servicios urbanos privatizados (Aguas Argentinas, Edenor, Edesur, etc.) como los grandes promotores (developers) de la restructuración territorial metropolitana. Podríamos utilizar la expresión de fragmentación administrativa para describir la delimitación de perímetros de intervención diferenciados en los barrios más humildes, con el riesgo consiguiente de crear una ciudad a dos o tres velocidades.

Por otra parte, es necesario destacar la acción de organizaciones no gubernamentales, cada día más presentes en las poblaciones modestas, así como el rol de las asociaciones de habitantes y las iglesias de las zonas "desfavorecidas" del Sur de la capital y de la periferia empobrecida. Todas ellas desarrollan, a su manera, políticas sociales territorializadas de lucha contra la pobreza, definiendo de esta manera una nueva serie de perímetros ad hoc. No obstante, es posible que estas intervenciones converjan, ya que en todas partes se experimentan nuevas formas de asociación de lo público, de lo privado y de lo asociativo, según configuraciones muchas veces inéditas. En una situación de crisis social y política aguda, el Plan Aguas más Trabajo, lanzado en marzo del 2004 por la Presidencia de la República para dotar de agua potable a 400.000 personas -de las aproximadamente dos millones excluidas de la red de alcantarillado en las zonas más pobres, en los márgenes de la ciudad- es un ejemplo de las formas hibridas de asociación público-privada. Este dispositivo asocia, según un montaje financiero, político y técnico complejo, al Estado, a la Municipalidad de la Matanza, a las cooperativas de trabajo y al operador de la concesión, en aquel entonces, Aguas Argentinas (Prévôt-Schapira, 2005). 


\section{La fragmentación socio-espacial: desintegración social y desarticulación urbana.}

La temática de la multiplicación de los actores y de los perímetros de intervención en la ciudad nos incita necesariamente a abordar la dimensión socio-espacial de la fragmentación urbana. Es en este contexto que la utilización de esta noción ha sido objeto de grandes polémicas. Muchos de sus detractores han hecho hincapié en la imprecisión y en la ambigüedad propia de tal vocablo, el cual supondría la existencia de un pasado urbano mítico, a su vez armonioso y cohesivo. Se puede leer así con interés la contribución de Genestier (2002) donde denuncia la tácita influencia de un ideal holista y la nostalgia del Estado como único preceptor de lo social. En otro registro, Vidal Rojas (2000) se propone subvertir la ya clásica asociación entre fragmentación y crisis urbana, subrayando que "la ciudad siempre es un conjunto de segmentos más o menos discontinuos, lo que constituye su esencia misma" y "que la ciudad evoluciona según una dinámica de cambio permanente, ligada entre otras cosas, a la evolución tecnológica, económica y social”. Por último, los trabajos de González Téllez (2004) sobre la sociabilidad pública en la ciudad de Caracas analizan la génesis de los modos de relación entre dos fragmentos de la ciudad, que corresponden a dos maneras de ver y de pensar los espacios, a "voces discordantes" frente al orden establecido, en un país donde la cultura urbana nunca fue "incluyente". Analizando los diferentes modelos de ciudad, desde la ciudad colonial a la ciudad de masas de los años setenta y a la ciudad violenta de los años noventa, González Téllez recalca el "desencuentro" entre un discurso institucional y el sentimiento de una "ciudad disimulada”, marcada por su falta de convivencia. Este término se impuso en la década de los noventa en las grandes metrópolis latinoamericanas como un nuevo eje legislativo para el establecimiento, no sin debates y controversias, de reglas de convivencia en un espacio público percibido a la vez como amenazado y violento ${ }^{2}$.

En un artículo de L'Information Géographique, Rhein y Elissalde (2004) nos encomiendan tener presente que se pueden distinguir dos posturas en los análisis de la fragmentación urbana: aquella que insiste en el fortalecimiento de las diferencias, las que engendrarían nuevos antagonismos y comportamientos privilegiando la separación, acentuando así las rupturas y las fronteras, y aquella que privilegia la capacidad de la ciudad, como punto de encuentro e intercambio, capaz de producir cohesión social y coherencia urbana, en un territorio que no puede ser reducido a la simple yuxtaposición de los grupos que lo componen. Estas dos posturas traducen en gran medida las tensiones que atraviesan el espacio urbano. Evidentemente, no es nuestra intención negar todos los factores que permiten comprender lo que "hace sociedad", retomando la expresión de Donzelot (2003), a través de prácticas diversas de solidaridad y de las formas de sociabilidad existentes (tanto clientelistas, como participativas, o incluso comunitarias). Estas dinámicas de integración, a escala de barrio como de ciudad, han sido exhaustivamente estudiadas por antropólogos, sociólogos y politólogos.

\footnotetext{
2 En Buenos Aires, el año 2004, un nuevo código de convivencia, de carácter más represivo, inspirado por las políticas de "tolerancia cero", fue votado en un contexto de demanda creciente de seguridad, de exasperación de parte de los habitantes de la ciudad frente a la multiplicación de las manifestaciones de piqueteros y a la "invasión" de las calles, una vez caída la noche, por los cartoneros de la periferia. En México, el voto de la ley sobre la "cultura cívica" (1 ero de agosto 2004), que promovió la expulsión de numerosos comerciantes ambulantes, va en el mismo sentido y ha dado lugar a importantes controversias.
} 


\section{La ciudad "fragmentada": de la desolidarización espacial a las estrategias de sus habi- tantes}

No obstante, si se considera junto a Jean Rémy (2002) que la fragmentación debe ser ante todo concebida como un proceso, podemos efectivamente entender el interés despertado por esta noción en América Latina durante la década pasada, en un periodo caracterizado por el repliegue del intervencionismo estatal y por la aparición de nuevas modalidades de gobierno de la ciudad, dejando el camino libre para la participación de nuevos actores privados y asociativos. En efecto, las diferentes lecturas de la fragmentación comparten la idea de correlación entre las dinámicas espaciales de la metropolización (suburbanización, movilidad, emergencia de centralidades periféricas) y los procesos de fracturación de la unicidad urbana, resultado del agravamiento de las desigualdades sociales, de formas de desolidarización y de reagrupamiento según afinidades. Paralelamente al proceso de metropolización y de globalización económica, se pueden observar en el interior de las ciudades tendencias a la división, con la aparición de fronteras urbanas ligadas a la gentrificación, así como procesos de aumento de la heterogeneidad en el seno mismo de los barrios consolidados (Smith, 1996).

\section{Nuevos dibujos de la ciudad latino-americana}

Las substanciales transformaciones que han conocido tanto el tejido urbano como el armazón productivo de las grandes urbes latinoamericanas han reactivado el debate sobre la estructura y la modelización de estas ciudades. El modelo construido sobre la lógica aereolar de la centralidad y de los sectores (Borsdorf, 1976) fue descartado progresivamente gracias a reflexiones sobre los fenómenos de discontinuidad y de atomización de sus unidades funcionales. "Dual", "cuarteada” o "archipiélica” (Mollenkopf y Castells, 1991; Marcuse, 1989; Janoschka, 2002), la ciudad latinoamericana parece estar siendo pensada cada vez más a través de las imágenes de división, de separación y de fragmentación. Las estructuras segregativas sobre las cuales se construyó la ciudad latinoamericana se han mantenido sin lugar a dudas durante todo este periodo. A pesar de la diversificación de los productos y de las localizaciones residenciales destinadas a los sectores de altos ingresos, la auto-segregación de las élites urbanas se ha perpetuado y, en ciertos casos, se ha reforzado. En tanto, en la frontera de las grandes metrópolis, el proceso de suburbanización de la población de bajos recursos continúa, en gran medida bajo la responsabilidad de un Estado que ha favorecido lógicas de localización de la vivienda social basadas sólo en el criterio del precio del suelo (con la consiguiente concentración de la pobreza) e ignorando el problema de los costos de desplazamiento de los más pobres desde las periferias ${ }^{3}$. No obstante, la acción del mercado inmobiliario y los efectos inducidos por la globalización económica han desembocado en una mayor imbricación de los diferentes territorios urbanos y en el cambio de la escala de la segregación (Sabatini, Cáceres y Cerda, 2001). La tendencia a la verticalización y a la densificación de los barrios consolidados a través de las torres segurizadas y la construcción de barrios cerrados en sectores periféricos modestos han favorecido una mayor difusión de las clases medias superiores bajo el modelo del enclave residencial. Paralelamente al avance de la

\footnotetext{
3 Las consecuencias nefastas de la distancia al centro son un elemento central del habitar cotidiano de los residentes de la Provincia de Buenos Aires al punto que los habitantes que viven en la extrema periferia de La Matanza se auto-llaman "la gente de los kilómetros".
} 
frontera residencial, se puede también observar el redescubrimiento de un interés por los cascos históricos degradados por parte de ciertas fracciones de la élite, como es el caso del renacimiento de Palermo Viejo, y de sus extensiones de Palermo Soho y de Palermo Hollywood, de la mano de una creative class, retomando la expresión de Florida (2002), que hace del consumo cultural uno de los principales ejes de su urbanidad.

Mapa 1. Entre barrios privados y villas miseria: de un patrón de segregación centro-periferia....

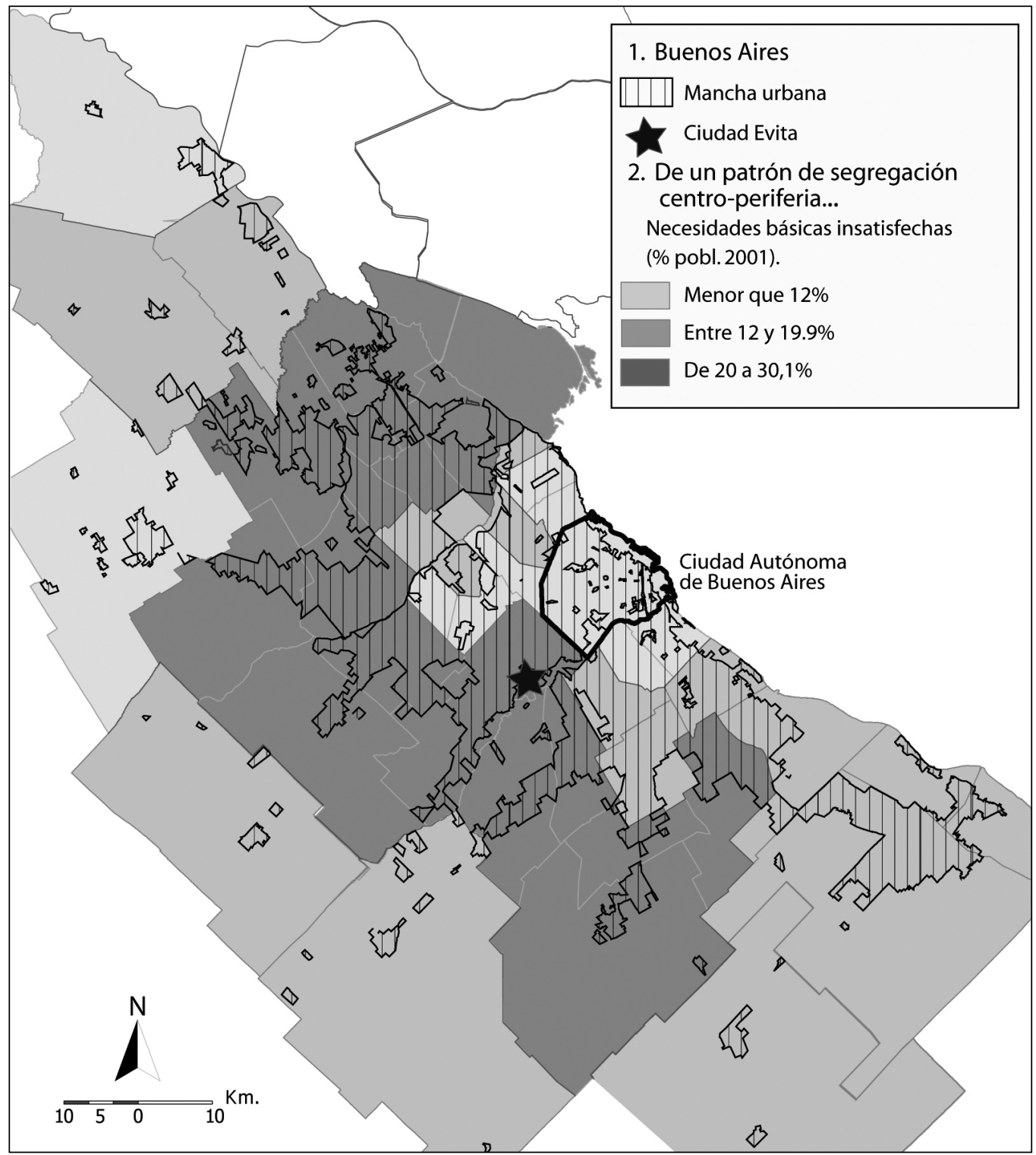

Fuente: Realización de Cattaneo, R. con base en cartografía de la Oficina Área Metropolitana de la Subsecretaría de Urbanismo y de Vivienda del Gobierno de la Provincia de Buenos Aires (Julio 2008) y Censo Nacional de Población, Hogares y Vivienda (2001). 
Mapa 2. ... a un mosaico espacial y social.

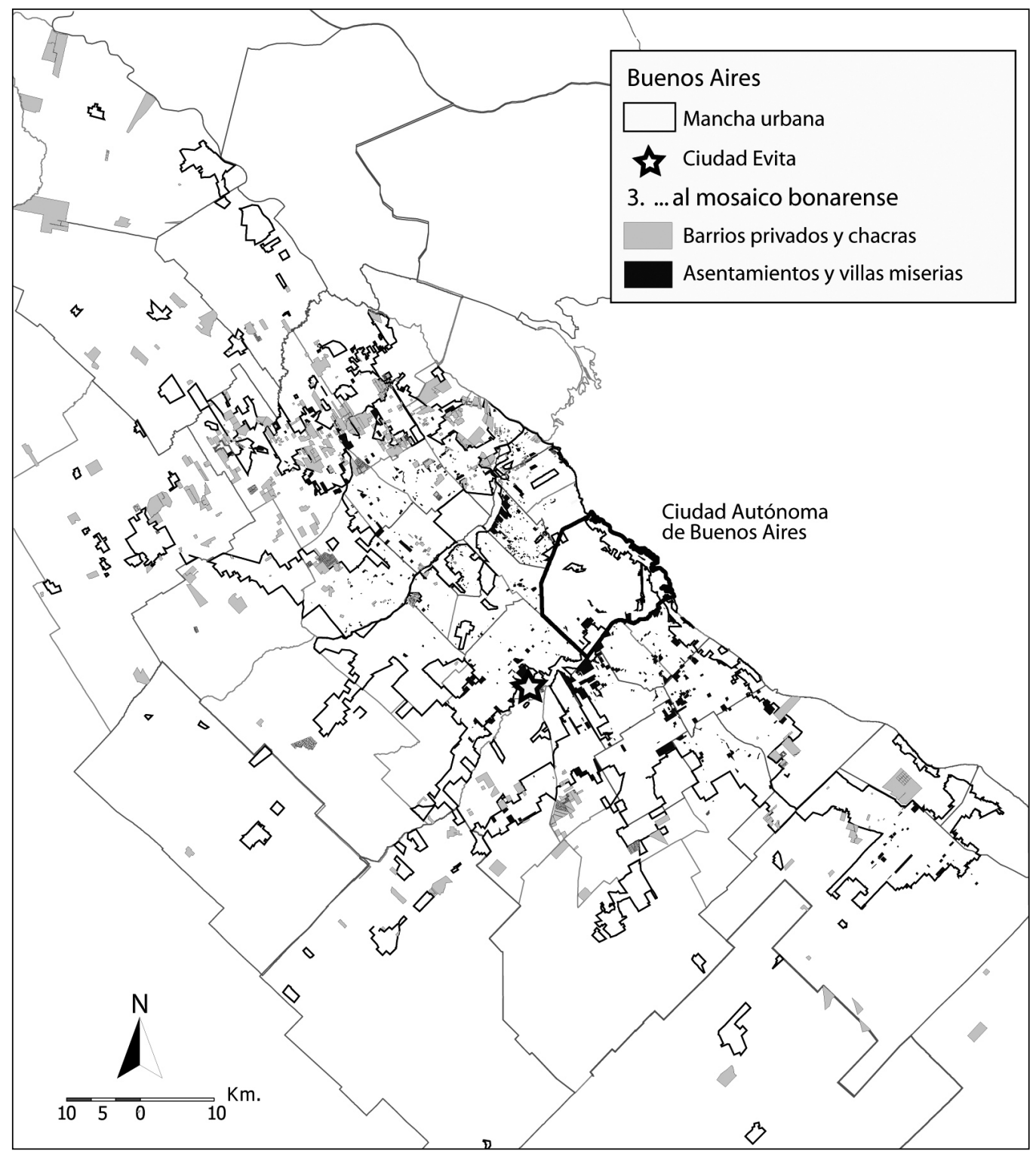

Fuente: Realización de Cattaneo, R. con base en cartografía de la Oficina Área Metropolitana de la Subsecretaría de Urbanismo y de Vivienda del Gobierno de la Provincia de Buenos Aires (Julio 2008).

Por último, el desarrollo de vías de comunicación rápida y la relativa ubicuidad de los "artefactos de la modernidad", como los centros comerciales, arriman a la ciudad latino-americana al modelo de la ciudad genérica descrita por Koolhaas (1995), en tanto que el principio de centralidad es subvertido por la aparición de numerosos núcleos corporativos y de servicios en lo que ya no puede ser calificado de periferia. En un ambiente intelectual a la vez marcado por una lectura crítica de la globalización económica pero sensible a las hipótesis del 
urbanismo post-moderno (Dear y Flusty, 1998), las tentativas de modelización de la ciudad latinoamericana han recurrido a las imágenes de la fragmentación y del mosaico para designar esta emancipación de las células urbanas del principio de contigüidad. Estaríamos, así, frente a una nueva fase del desarrollo de las ciudades latinoamericanas, marcada por la fragmentación y la exclusión (Borsdorf et al., 2007), en consonancia con las hipótesis de Soja (2000) sobre la postmetropolis. Los procesos de territorialización y de desterritorialización asociados al capitalismo tardío corroerían de esta manera nuestras categorías habituales de descripción de la ciudad (centros, suburbios, área metropolitana, etc.), y nos invitarían a reflexionar sobre sus procesos de heterogeneización.

\section{¿Ciudad cerrada, ciudad privatizada, ciudad fragmentada?}

El desarrollo formidable durante las dos últimas décadas de los productos inmobiliarios cerrados no dejó de provocar un notorio malestar, en especial en una sociedad animada por la pasión igualitaria como en el caso argentino. La fragmentación del tejido urbano y la cristalización de sus fronteras por medio de vallas y de servicios de seguridad privados manifiestan un cambio en la relación de la ciudad con sus habitantes. Low (2005) identifica así el miedo como el principal motor del envallamiento de la ciudad. En una situación de ahondamiento de las desigualdades sociales y de diferenciación creciente de los destinos de las distintas células urbanas, la fragmentación física de la ciudad parece ser el modo de gestión contemporáneo de los riesgos, tanto reales como imaginados, de la urbanidad. Al respecto, no deja de ser interesante notar la recuperación de los principios del "urbanismo defensivo", propuestos por Newman (1973) para la reconquista de barrios pobres fuertemente degradados, por operaciones inmobiliarias destinadas a los segmentos más acomodados de la sociedad. Semi-privatización de los espacios públicos, búsqueda de la visibilidad y co-vigilancia permanente son, así, principios recurrentes de todos estos nuevos proyectos. Pero estos fenómenos no son exclusivos de los barrios de la clase alta. Muros, rejas y portones se han multiplicado en barrios consolidados de la clase media e inclusive en barrios de vivienda social o marginales, constituyendo así verdaderos barrios privados informales (Vidal-Koppmann, 2003).

Sin embargo, estas conclusiones sufren de los netos desequilibrios existentes en la producción científica sobre los barrios cerrados. Si se han llevado a cabo esfuerzos, a veces exhaustivos, de identificación, localización y conteo de las unidades residenciales cerradas en América Latina, el número de trabajos que han analizado las motivaciones y las sociabilidades "comunitarias" es inferior, y aun menor si nos interrogamos sobre las relaciones potenciales a través de los muros. A partir de investigaciones realizadas en la comuna de Huechuraba (Santiago), Salcedo y Torres (2004) sugieren reexaminar la visión de los barrios cerrados como enclaves, favoreciendo la lectura de la valla como una frontera más que como un muro. Multiplicando las oportunidades de trabajo y colaborando a la recalificación urbana de los espacios periféricos, los enclaves conllevarían de esta manera a una reducción de la segregación y a una mejora de la situación de los más pobres. Pero desde el artículo fundador de Chamboredon y Lemaire (1970) sabemos que la relación entre proximidad espacial y cercanía social no es unívoca. En el caso de Buenos Aires, las relaciones entre "los que ganaron" y su entorno consiste muchas veces en simples operaciones de pacificación (obras de "beneficencia" y empleos "domésticos") en un ambiente de profunda desconfianza (Svampa, 2001). Nos parece así que la validación de la hipótesis 
de la fragmentación exige superar la focalización en la descripción de las formas urbanas para volcarse a la observación empírica del cuerpo social y de sus dinámicas internas.

\section{Métodos y escalas de observación}

Nuestras lecturas de la ciudad no son independientes de los métodos y de las escalas de observación seleccionadas, las cuales forjan a su vez las representaciones urbanas de sus habitantes. A partir de los años ochenta, el progreso de las herramientas de cartografía y de la reflexión sobre la aplicación de políticas públicas territorializadas de lucha contra la pobreza favoreció la adopción de lecturas más finas y más complejas de los procesos de espacialización de la pobreza y de las desigualdades. En cierta medida, la incorporación del carácter multidimensional de la pobreza a la construcción de indicadores matemáticos, asociada a una representación cartográfica de datos desagregados a pequeña escala, evidenció la heterogeneidad de estos espacios. Las grandes divisiones socio-espaciales que estructuraron el desarrollo histórico de estas ciudades se mantienen e, incluso, en ciertos casos aumentan, pero estas nuevas metodologías permiten advertir una imbricación mayor de las zonas pobres y de las zonas acomodadas, y revelan nuevas proximidades espaciales en un mosaico complejo de fragmentos urbanos (Dureau et al., 2004). Sin embargo, su mayor disponibilidad no autoriza el escatimar una reflexión sobre las unidades de análisis más apropiadas para el estudio de los fenómenos de segregación y de fragmentación urbana. En el caso parisino, el debate sobre la "secesión" de las clases medias se explica en gran medida por la escala seleccionada para el estudio de la estratificación social de la ciudad. Para Preteceille y Oberti (2004), la tesis de Maurin (2004) sobre la ruptura entre clase media y ciudad se ve invalidada por la selección de una escala de estudio sumamente pequeña, la manzana de una cincuentena de viviendas, ya que muestra convincentemente que la homogeneización a nivel de las manzanas no excluye una importante mixtura social a nivel de los barrios (IRIS ${ }^{4}$ ).

En el marco de estas investigaciones, la imagen del mosaico es la figura más frecuentemente utilizada para describir el resultado cartográfico de estos tratamientos estadísticos. Los investigadores del CEBRAP5 de Sao Paulo confeccionaron, por ejemplo, una completa cartografía del área metropolitana de Sao Paulo a la escala de las unidades de base del censo -21.000, para un conjunto de 18 millones de personas-, por medio de la construcción de un índice de privación (deprivation indicator) y de la introducción de variables discriminantes como la tasa de homicidios y el dominio de la lengua portuguesa. En una ciudad caracterizada por situaciones de desigualdad extrema, se puede observar que las zonas de fuerte tensión social (calificadas de hot spots) y las "hiperperiferias", suerte de quistes cristalizados de pobreza (desempleo, baja tasa de escolarización, juventud de la población), complejizan el esquema dual centro/periferia, en tanto que numerosos enclaves residenciales brotan en la periferia oriental, y que las microinvasiones prosiguen en los espacios intersticiales de un centro en plena mutación.

\footnotetext{
4 Ilots regroupés pour l'information statistique: unidad de base para la difusión pública de la información estadística del territorio francés (aproximadamente 50.800 unidades).

5 www.centrododametropole.org.br (textos y mapas en línea).
} 
En México, en una escala más local, los procesos de fragmentación urbana pueden ser observados en los barrios acomodados del sud-oeste del Distrito Federal, en los cuales se concentran los barrios cerrados, las escuelas bilingües, los clubes deportivos y los malls, como en la delegación Álvaro Obregón (Guerrien, 2004). La cartografía de un indicador socio-económico construido sobre la base de un análisis multifactorial de las $\mathrm{AGEB}^{6}$ revela la contigüidad entre algunas de las zonas más ricas de la Ciudad de México y algunas de las más modestas, "una proximidad que abre la puerta a todos los tipos de miedo y de resentimiento, y a la multiplicación de los cercos, de los guardias armados y de los check-points. Evocando las imágenes del análisis topológico, el término de fragmentación es esgrimido para describir "un archipiélago de espacios conexos... o dicho de otra manera, un espacio al interior del cual todos los puntos pueden ser vinculados sin salir de sus fronteras".

\section{La fragmentación en el corazón de una sociedad polarizada.}

La hipótesis de la desarticulación creciente de los territorios urbanos, asociada a una integración diferenciada en los grandes flujos de la globalización capitalista, tiene como correlato social el postulado de la dualización de la estructura de clases de estas metrópolis. Sassen (1991) predice así una evolución de la estratificación social de las ciudades globales hacia formas similares a las de un reloj de arena gracias a la expansión de las funciones gerenciales y de consultoría a la aparición concomitante de un proletariado de servicios, sometido y dependiente de esta nueva elite urbana. A pesar del carácter sugestivo de estas propuestas, la evidencia empírica contradice los vaticinios sobre la dualización social. Préteceille (2006) prefiere más bien recalcar la inercia de las estructuras sociales de una gran metrópolis como el área metropolitana parisina -l'île de France-. Si los sectores globalizados de la economía han sido las actividades más dinámicas en el plano de la creación de nuevos empleos, sus efectos sobre la repartición de las categorías socio-profesionales tanto superiores como populares han sido tan sólo marginales. Pero aun en situaciones de transformaciones profundas de la estructuración social, la información estadística disponible no acredita la idea de la polarización del tejido social. Estudiando el mercado de trabajo de la ciudad de Santiago, De Mattos et al. (2005) concluyen que las categorías sociales que han conocido el crecimiento más importante son las categorías de empleo intermedias y que sus patrones de localización favorecerían tendencias a la desagregación y a la moderación de las desigualdades sociales. Las lecturas científicas sobre el rol de la nebulosa de las clases medias en las ciudades parecen así contradictorias. ¿Debemos considerar a los grupos intermedios como un simple residuo, destinados a desaparecer, vapuleados por los efectos de las políticas de reajuste y por las crisis cíclicas de una economía globalizada (Sassen, 1991)? ¿Condenarlos por su travestismo político y su mimetismo cultural (Moulian, 1997)? ¿O esperar de ellos la animación de movimientos progresistas de recuperación y de rehabilitación de los cascos antiguos a través de nuevas modalidades de urbanidad (Bidou, 2003)?

Quizás sea necesario acotar entonces que la diversidad de estas hipótesis refleja la heterogeneidad propia de las clases medias. La polarización de la estructura social latinoamericana ha

$6 \quad$ AGEB: unidades geo-estadísticas de base, definidas por el Instituto Nacional de Economía, de Geografía y de Informática -INEGI-, que agrupan un máximo de algunos miles de habitantes. 
acentuado los procesos de fracturación y de desarticulación de los grupos intermedios, dividiendo sus destinos en direcciones discordantes. Si una pequeña capa ha logrado adoptar las practicas de consumo y los valores de las clases superiores (Svampa, 2001), la mayoría parece ser víctima de la multiplicación de las nuevas formas de pobreza urbana (Kessler y Di Virgilio, 2002). La noción de fragmentación trataría de traducir las dificultades del proyecto político y social representado por las clases medias en Argentina. En una situación de crisis, su unidad simbólica fue obstaculizada por múltiples expresiones de atomización social y de competencia exacerbada entre grupos e individuos por la apropiación de recursos escasos. Las consecuencias espaciales de esta situación son tanto más notorias que la capacidad de controlar su contorno urbano es uno de los recursos políticos más frecuentemente movilizados en el marco de estas pugnas (Merklen, 2006).

\section{Pensar la fragmentación a través de la fábula inacabada de Ciudad Evita}

Pero la fragmentación no se reduce a un "cara a cara” entre ricos y pobres. De manera quizás más significativa, en la periferia de Buenos Aires, incluye los procesos de micro-fragmentación en la escala de la manzana, del barrio y de la comuna. Inscribiéndonos en la filiación de las "exploraciones geográficas" de William Bunge (Merrifield, 1995), el trabajo de campo realizado en Ciudad Evita, en la comuna de La Matanza, una de las más populares de la corona suburbana de Buenos Aires, nos permitió examinar una dinámica de micro-fragmentación que fue construida y exacerbada por las irregularidades de la caótica historia de los suburbios y por la violencia de las crisis económicas y políticas que han golpeado a la gran metrópolis argentina. Esta perspectiva tiene como objetivo el análisis de la dimensión política, y las temporalidades y la subjetividad de los habitantes, en una sociedad atribulada por el miedo al desclasamiento (Merklen y Prévôt-Schapira, 2003) ${ }^{7}$.

Con sus cerca de 90.000 habitantes, Ciudad Evita, ubicada en la municipalidad de La Matanza, la más populosa y pobre del conurbano, nos parece ser el espacio más apropiado para el análisis de las dinámicas de fragmentación en acción en los espacios periféricos de Buenos Aires. Concebida a principios de la década de los cincuenta como una ciudad-jardín modelo e inspirada por los principios de E. Howard, Ciudad Evita es una de las obras más emblemáticas del periodo peronista: una ciudad de quince mil chalets de tipo californiano (de los cuales sólo 5.000 llegaron a ser construidos), vistos como el símbolo de la movilidad social ascendente asociada al peronismo, promesa inscrita en el trazado mismo de su primera circunscripción, con la forma del perfil de Evita. El proyecto de acercamiento de los valores y condiciones de vida de obreros y de la clase media era así ratificado por la elección de la casa individual de tipo chalet como unidad habitacional de base. Pero a partir del golpe militar de 1955, el territorio de Ciudad Evita fue desmembrado progresivamente según una sucesión compleja de agresiones simbólicas y urbanísticas, y de relleno de sus espacios intersticiales por un hábitat para la pequeña clase media (operaciones construidas por sindicatos, cooperativas de autoconstrucción, etc..). No conforme con desbautizar la localidad, el régimen militar trato

\footnotetext{
Estas reflexiones se sustentan del trabajo de campo realizado junto a Denis Merklen en Ciudad Evita y del informe para el programa PUCA «Habiter quelle ville», Cf. Merklen y Prévôt-Schapira, 2003.
} 
de desdibujar el perfil de Evita a través de la implantación de varios programas de vivienda "transitorios". En el marco de una política brutal de erradicación de las villas en la Ciudad Autónoma de Buenos Aires, varios núcleos habitacionales transitorios fueron definidos dentro del perímetro de Ciudad Evita, a la espera de los conjuntos de monobloques en construcción en la proximidad, los que serian a su vez ocupados ilegalmente por una nueva ola de pobres urbanos. En un contexto marcado por las crisis cíclicas, las fronteras de este espacio fraccionado por la acción pública y popular se cristalizan, creando grupos localizados con intereses opuestos: habitantes de los chalets amenazados por la menos-valía generada por la proximidad de la "marginalidad urbana", villeros expulsados manu militari de la ciudad a la espera de una reparación histórica, habitantes "transitorios" desde hace treinta años.

Mapa 3. Ciudad Evita: del modelo ciudad-jardín a un territorio disputado y fragmentado.

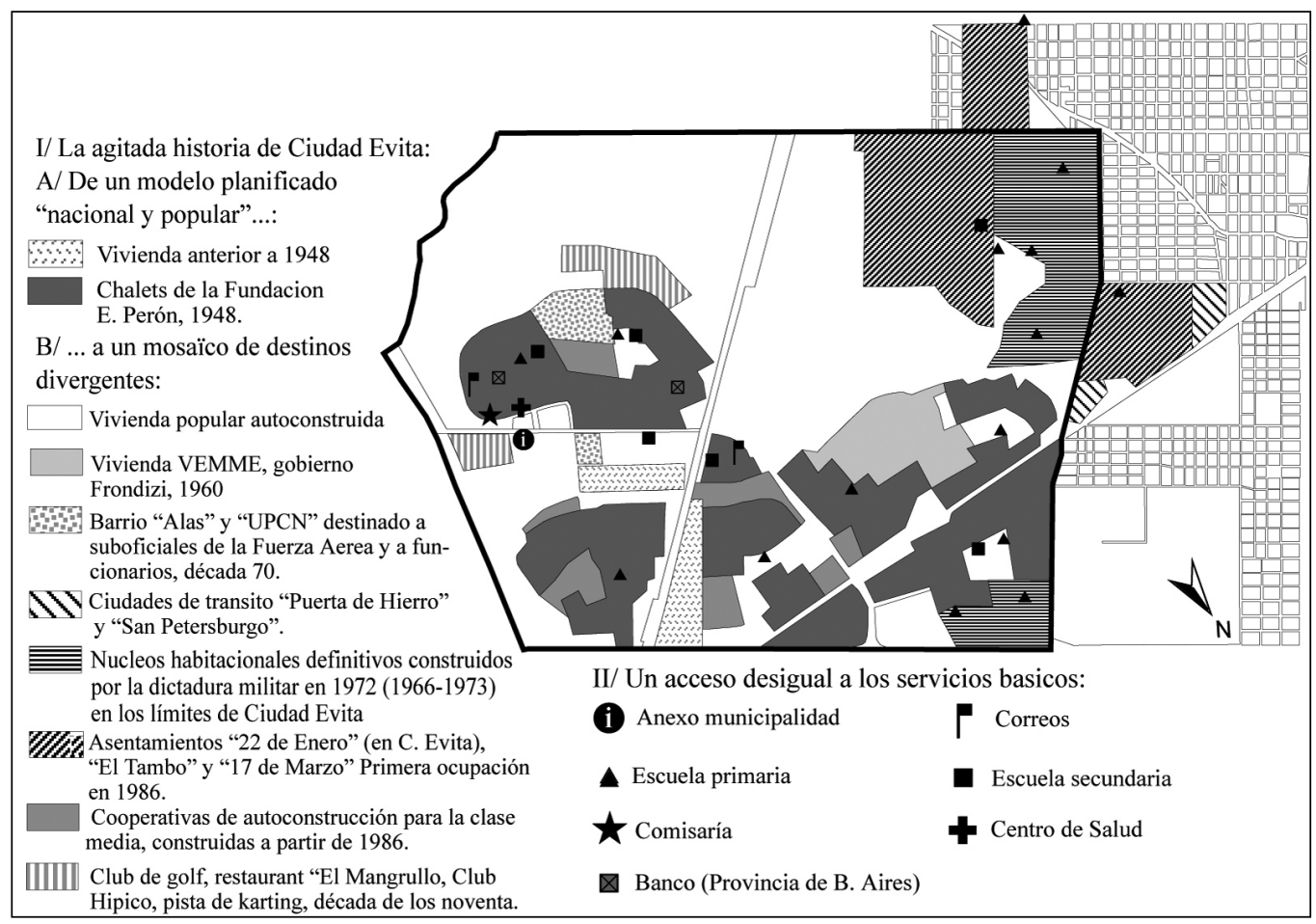

Fuente. Realización de Cattaneo, R. con base en Merklen, D. y Prévôt-Schapira, M.-F., 2003.

Podemos observar que no queda prácticamente nada de la sociabilidad de la Ciudad Evita de los años 50 y 60, de la ciudad-jardín modelo construida por Eva Perón, y habitada por familias obreras. Una sociabilidad de "clase media" se introdujo en los chalets-modelos, situados a solo veinte minutos de la capital y dotados de equipamientos de calidad, mientras que de manera concomitante, la marginalidad se instalaba sobre los márgenes de su territorio (ciudades de tránsito, zonas de ocupación colectiva, cités, poblaciones pobres). Los puntos de intercambio, de encuentro y de co-presencia son escasos: los transportes, los comercios y algunos espacios lúdicos, pero sobre todo las dos únicas instituciones que poseen una vocación ecuménica, la escuela y las iglesias. Pero bajo la presión del empobrecimiento generalizado y 
de la disminución de los recursos destinados a la educación, las escuelas se han transformado en verdaderos terrenos de escondites de apoderados de distinto nivel socio-económico. Cuando los residentes de las poblaciones periféricas logran inscribir a sus hijos en un colegio situado en el área de los chalets, los apoderados inician una verdadera "migración escolar" para proteger a su progenie de las "malas juntas". Se establece de este modo un efecto dominó, una verdadera onda de choque que atraviesa estos espacios desde la periferia hasta el Sur de Ciudad Evita. La población escolar de la circunscripción IV de Ciudad Evita ha migrado así de la Escuela $N^{\circ} 152$, situada sobre su territorio, hacia la Escuela No 150, dejando la anterior a los habitantes de los asentamientos y de los monobloques. En la parte Sur, Ciudad Evita funciona como una suerte de barrio cerrado, protegido de la progresión de las clases populares por una verdadera zona de contención declarada zona de patrimonio histórico-ecológico en 1997, tras la movilización de los pobladores "históricos" de Ciudad Evita. En cambio, en su fracción norte, la proximidad con los barrios marginales y empobrecidos ha conllevado a una desvalorización del precio de suelo.

Para los habitantes pobres, ninguna institución pública ofrece la posibilidad de construir una sociabilidad común con sus vecinos más acomodados. Por consiguiente, a diferencia de la zona de los chalets, todo contribuye a valorizar la importancia del "barrio", siendo éste un factor esencial para analizar la construcción de territorios separados. En efecto, los barrios se encuentran sometidos a una competencia creciente por el acceso a los beneficios de la ayuda social, siempre insuficiente debido a la persistencia endémica de la crisis. Bajo el control del sistema político (en realidad, de las diferentes corrientes del peronismo), los barrios se ven obligados a organizarse en función de la negación del otro, percibido como el beneficiario potencial de los recursos por los cuales hay que luchar, "nosotros, que siempre fuimos dejados de lado".

Ciudad Evita refleja un Gran Buenos Aires que ha sido a la vez cultivado y abandonado por la acción pública, por el poder de Estado, y, a la manera de un contrapunto, "producido" por los diferentes repertorios de la acción colectiva de las clases populares. La periferia aparece, de esta manera, como un gigantesco espacio fragmentado, por un patrón de urbanización en células más o menos autónomas, y por las desigualdades generadas por el funcionamiento del mercado inmobiliario, pero igualmente como resultado de una acción política dominada por la intermitencia y la sobre-determinación política de los conflictos. Dentro de esta perspectiva, el análisis de la ciudad en términos de fragmentación parece ser más operatorio que la lógica centro/periferia que había dominado hasta hoy, debido a la multiplicación de las fronteras en un contínuum que se empobrece. En el caso del Gran Buenos Aires, la fractura se ahonda entre los pobres y los "privilegiados" en una inmensa periferia cada vez más dividida, de la cual emergen puntualmente los enclaves residenciales.

\section{Conclusión}

Debido a la magnitud de los procesos de desregulación, del aumento de la polarización social y del empobrecimiento creciente que se observa en la gran mayoría de las ciudades latinoamericanas, la investigación urbana ha privilegiado la temática de la fragmentación bajo sus diferentes aspectos. Nos parece necesario subrayar la importancia de la dimensión política en estos procesos de fragmentación. La sucesión irregular de políticas de vivienda y la 
actitud ambivalente frente a las dinámicas de loteo informal y popular sentaron las bases de una organización en mosaico de los suburbios bonaerenses. Estas discontinuidades pueden cristalizarse en fronteras bajo la influencia de un sistema político basado en un modelo de organización clientelista y en la lógica del control y de la movilización del entorno urbano como un recurso político negociable en las diferentes arenas -comunal, provincial, nacionalde gobierno. Pero la fragmentación también sobreviene en los intersticios de una sociedad polarizada y apremiada por el temor al desclasamiento. En una situación de mayor fragilidad social y de heterogeneización de las trayectorias sociales y residenciales, tanto los individuos como los grupos intermedios se piensan en términos antagónicos de competencia entre unos y otros para conservar su estatus social. La fragmentación se establece, así, como el principal modo de gestión de la diferencia en una sociedad en curso de atomización.

No obstante, en las grandes urbes latinoamericanas, la última década ha visto también surgir nuevas formas de gobernanza urbana y de organización social, que mitigan la dinámica de fragmentación. Después de un largo eclipse durante el periodo desarrollista, durante el cual lo urbano no era considerado más que en términos sectoriales (vivienda, transporte, servicios urbanos), podemos observar el retorno de una reflexión sobre la ciudad en sus dimensiones políticas y sociales. Esta nueva filosofía urbana ha influenciado considerablemente las políticas públicas lanzadas por las alcaldías de estas grandes ciudades, favoreciendo la adopción de políticas audaces e innovadoras para enfrentarse a la "nueva cuestión urbana". El ejemplo del presupuesto participativo de Porto Alegre es el más conocido y ya ha hecho escuela en toda Latinoamérica. Menos conocida es la apuesta de la redensificación de los espacios céntricos, como en México, pero ya no con la sola visión patrimonialista de la rehabilitación de los barrios históricos de los años setenta, sino también con el objetivo de crear empleos y diversificación social de sus habitantes, como en Sao Paulo, o tratando de favorecer las movilidades como en Bogotá. Es quizás en esta ciudad donde ha sido más audaz la manera de administrar la ciudad, debido al impacto simbólico de las políticas llevadas a cabo y a la continuidad inusitada de los gobiernos urbanos, dando prioridad a la movilidad de los habitantes, peatones y ciclistas, pero sobre todo, a los usuarios de los transportes colectivos. La voluntad de hacer una ciudad más democrática y más igualitaria fue simbolizada por la creación de bibliotecas públicas, de parques, el ensanchamiento de las aceras, el establecimiento de un nuevo sistema de transporte, el Transmilenio, pero antes que nada por el desarrollo de una cultura cívica compartida por todos para reducir la violencia y el miedo "que deshacen la ciudad".

\section{Referencias bibliográficas}

Ballent, A. (2005). Las huellas de la politica: vivienda, ciudad, peronismo, 1943-1955. Bernal: Universidad Nacional de Quilmes.

Bidou-Zachariasen, C. (2003). Retours en ville. París: Descartes et Cie.

Borsdorf, A. (1976). Valdivia und Osorno. Strukturelle disparitäten und entwicklungsprobleme in chilenischen mittelstädten. Tübinger Geograsphische Studien, 69.

Borsdorf, A.; Hidalgo, R. \& Sánchez, R. (2007). A new model of urban development in Latin America: the gated communities and fenced cities in the metropolitan areas of Santiago de Chile and Valparaíso. Cities, 24, 5, 365-378. 
Castels, M. \& Mollenkopf, J. (Ed.) (1992). Dual city: restructuring New York. New York: Russel Sage Foundation.

Chamboredon, J.-C. \& Lemaire, M. (1970). Proximité spatiale et distance sociale: les grands ensembles et leur peuplement. Revue Française de Sociologie, 11, 1, 3-33.

Ciccolella, P. (1999). Globalización y dualización en la Región Metropolitana de Buenos Aires. Grandes inversiones y reestructuración socioterritorial en los noventa. EURE, 25, 76, 5-27.

De Mattos, C.; Riffo, L.; Yáñez Warner, G. \& Salas, X. (2005). Restructuración del mercado metropolitano de trabajo y cambios socio-territoriales en el gran Santiago. Santiago: IEUTPUC.

Dear, M. \& Flusty, S. (1998). Postmodern urbanism. Annals of the Association of American Geographers, 88, 50-72.

Donzelot, J. (2003). Faire société: la politique de la ville aux Etats-Unis et en France. París: Editions du Seuil.

Dureau, F.; Barbary, O.; Gouëset, O. \& Pissoat O. (2004). Villes et sociétés en mutation. Lectures croisées sur la Colombie. París: Anthropos.

Florida, R. (2002). The rise of the creative class and how it's transforming work. Leisure, community and everyday life. New York: Basic Books.

Genestier, Ph. (2002). La rhétorique de la ville fragmentée, ou quand l'idéal holiste est délégué à l'échelon local. En F. Navez-Bouchanine (Dir.), La fragmentation en question. Des villes entre fragmentation spatiale et fragmentation sociale? (pp. 119-137). París: L'Harmattan.

González Téllez, S. (2004, diciembre). La segregación urbana en Venezuela. Conferencia doctoral presentada en el Institut des Hautes Etudes de l'Amérique Latine, París, Francia.

Gorelik, A. (1997). Buenos Aires en la encrucijada: modernización y política urbana. Punto de Vista, 59.

Graham, S. \& Marvin, S. (2001). Splintering urbanism: networked infrastructures, technological mobilities and the urban condition. London and New York: Routledge.

Guerrien, M. (2004). Transformation et fragmentation des espaces urbains. Le cas de la zone métropolitaine du bassin de Mexico. L'Espace géographique, 2, 1-17.

Jaglin, S. (2007). Décentralisation et gouvernance de la diversité: les services urbains en Afrique anglophone. En L. Fouchard (Dir), Gouverner les villes d'Afrique: etat, gouvernement local et acteurs privés (pp. 21-34). París: Karthala/CEAN.

Janoschka, M. (2002). El nuevo modelo de ciudad latinoamericana: fragmentación y privatización. Eure, 28, 85, 11-20.

Kessler G. \& Di Virgilio, M. (2002). La nueva pobreza urbana: dinámica global, regional y argentina en las dos últimas décadas. Revista de la CEPAL, 95, 31-50.

Koolhaas, R. (1995). The generic city. Rotterdam: 010 Publishers.

Laumonier, L. (2004). Le discours sur les villes en développement. Epistémologie de la notion de ségrégation urbaine. Tesis de geografía, Universidad de París VII, París, Francia.

Libertun de Duren, N. (2006). Planning à la carte: the location patterns of gated communities around Buenos Aires on a decentralized planning context. International Journal of urban and regional research, 30, 2, 308-327.

Low, S. (2005). Towards a theory of urban fragmentation: a cross-cultural analysis of fear, privatization and the state. Cybergéo, systemic impacts and sustaintability of gated 
communities in the City, Pretoria, South Africa. Rescatado en agosto de 2008 de http:// www.cyberheo.eu.

Marcuse, P. (1989). Dual city: a muddy metaphor for a quartered city. International Journal of Urban and Regional Reserch, 13, 4, 697-708.

Maurin, E. (2004). Le ghetto francais. Enquête sur le séparatisme social. París: Editions du Seuil.

Merklen, D. \& Prévôt-Schapira, M-F. (2003). Ciudad Evita. Action publique, logiques sociales et conflits territoriaux. Rapport du programme PUCA «Habiter quelle ville?: situation d'homogénéisation et (re)définition de l'urbain et de l'urbanité dans les Amériques», mimeo.

Merklen, D. (2006). Les pieds sur terre, le quartier comme figure de l'inscription territoriale des classes populaires. En M. Leclerc-Olive (Dir.), Affaires locales. De l'espace social communautaire à l'espace public politique, (pp. 121-136). París: Karthala-GEMDEV.

Merrifield, A. (1995). Situated knowledge through exploration: reflections on Bunge's geographical expeditions. Antipode, 27, 1, 49-70.

Moulian T. (1997). Chile actual: anatomia de un mito. Santiago: LOM.

Newman, O. (1973). Defensible space: crime prevention through urban design. London: Mac Millan Pub Co.

Pflieger, G. (2006). De la ville aux réseaux. Dialogues avec Manuel Castells. Suiza: Presses Polytechniques et Universitaires Romandes.

Préteceille, E. \& Oberti, M. (2004). Les classes moyennes, l'école et la ville: la reproduction renouvelée. Education et Sociétés, 14, 2, 135-153.

Préteceille, E. (2006) La ségrégation sociale a-t-elle augmentée: la métropole parisienne entre polarisation et mixité. Sociétés Contemporaines, 69, 69-93.

Prévôt-Schapira, M.-F. (1999). Amérique latine: La ville fragmentée. Esprit, 258, 128-144.

Prévôt-Schapira, M.-F. (2000). Du PAN au Plan de Justice Sociale: les politiques de lutte contre la pauvreté dans les banlieues de Buenos Aires. Annales de la Recherche Urbaine, 96, 132-143.

Prévôt-Schapira, M.-F. (2001). Fragmentación espacial y social: conceptos y realidades. Perfiles Latinoamericanos, 10, 19. 33-56.

Prévôt-Schapira, M.-F. (2005). Amérique latine: de la pertinence de l'usage de la notion de fragmentation urbaine. Bulletin de l'Association des géographes français, 4, 483-495.

Rémy, J. (2002). La fragmentation ou métamorphose de la ville. En F. Navez-Bouchanine (Dir.), La fragmentation en question. Des villes entre fragmentation spatiale et fragmentation sociale? (pp. 105-118). París: L'Harmattan.

Rhein, C. \& Elissalde, B. (2004). La fragmentation sociale et urbaine en débats. L'information géographique, 68, 2, 115-126.

Rusk, D. (1993). Cities without suburbs. Baltimore: John Hopkins University Press.

Sabatini, F.; Cáceres, G. \& Cerda, J. (2001). Segregación residencial en las principales ciudades chilenas: tendencias de las tres últimas décadas y posibles cursos de acción. EURE, 27 , $82,21-42$.

Salcedo, R. \& Torres, A. (2004). Gated communities in Santiago: wall of frontier? International Journal of Urban and Regional Research, 28, 1, 27-44.

Santos, M. (1990). Metropole corporativa e fragmentada. O caso de Sao Paulo. Sao Paulo: Nobel, Secretaria de Estado da Cultura. 
Sassen, S. (1991). The global city: New York, London, Tokyo. Princeton: Princeton University Press.

Smith, N. (1996). The new urban frontier. Gentrification and the revanchist city. Londres: Routledge.

Soja, E. W. (2000). Postmetropolis. Critical studies of cities and regions. Oxford: Blackwell Publishers.

Svampa, M. (2001). Los que ganaron. La vida en los countries y barrios privados. Buenos Aires: Biblos.

Vidal Rojas, R. (2000). Fragmentation urbaine: eléments pour une analyse multinodale de la fragmentarité. Tesis de doctorado, Facultad de Letras, Universidad de Lausanne, Suiza.

Vidal, L. (1995). Les mots de la ville au Brésil. Un exemple: la notion de "fragmentation". Cahiers des Amériques latines, 18, 161-181.

Vidal-Koopmann, S. (2003). Countries y barrios cerrados: nuevas formas de segregación urbana. Una aproximación al tema del crecimiento en el área metropolitana de Buenos Aires (Argentina). Geodemos, 6, 97-118. 